\title{
Investigating the Plant Growth Promoting and Biocontrol Potentiality of Endophytic Streptomyces sp. SP5 Against Early Blight in Tomato Seedling
}

\section{Sapna Devi}

Guru Nanak Dev University

Manish Sharma

Guru Nanak Dev University

Rajesh kumari Manhas ( $\nabla$ rkmanhas@rediffmail.com )

Guru Nanak Dev University

\section{Research Article}

Keywords: Streptomyces sp. SP5, Plant growth promotion, Biocontrol, Indole acetic acid

Posted Date: June 14th, 2021

DOI: https://doi.org/10.21203/rs.3.rs-568238/v1

License: (c) (i) This work is licensed under a Creative Commons Attribution 4.0 International License.

Read Full License 


\section{Abstract}

Background: Early blight (EB), caused by Alternaria solani, is one of the alarming diseases that restrict tomato production globally. Existing cultural practices and fungicide applications are not enough to control the early blight diseases. Therefore, the study aimed to isolate, identify, and characterize an endophytic Streptomyces strain exhibiting the potential to control early blight in tomato and also promote plant growth.

Results: From a Citrus jambhiri leaf, an endophytic Streptomyces sp. SP5 isolated with antagonistic activity against Alternaria solani, Colletotrichum acutatum, Cladosporium herbarum, Alternaria brassicicola, Alternaria alternata, Fusarium oxysporum and Fusarium moniliforme. It was identified as a Streptomyces sp. designated as SP5 through 16S ribosomal DNA sequence analysis. It also produced $40 \mu \mathrm{g} / \mathrm{ml}$ indole acetic acid which was further confirmed by TLC and HPLC analyses. Treatment of pathogen infected plants with Streptomyces sp. SP5 antagonist (culture cells/culture supernatant/solvent extract/ acetone precipitates) decreased the early blight disease incidence and significantly increased the various agronomic traits

Conclusion: The present study concluded that Streptomyces sp. SP5 possessed antifungal activity against different fungal pathogens and had significant potential to control early blight disease in tomatoes and also promote plant growth by producing IAA.

\section{Background}

Tomato is the second most widely used vegetable in the world after potato because of its high nutritional value (rich in vitamins $A$ and $C$ ) and the presence of lycopene and beta-carotene pigments $(1,2)$. Tomato crop occupies an area of $4.85 \mathrm{~m}$. ha. in the world with the production of 182.3 million tons and the productivity of $37.6 \mathrm{t} / \mathrm{ha}(3)$. In India, the tomato crop is grown in an area of 0.5 million ha with an annual production of 7.4 million tons (4). Continuous cropping of tomato plants leads to the prevalence of fungal diseases. One of the most devastating diseases of tomato is early blight caused by the necrotrophic fungus Alternaria solani (5). Leaf blight, stem blight, and apical fruit rot are the most damaging symptoms of the disease, and in severe cases, this can lead to complete defoliation (6). Many reports recorded early blight is responsible for a large proportion of total monetary loss sustained by tomato producers every growing season (7). Pesticide application is still a valuable and efficient method to controlling plant diseases in modern agriculture. However, the use of agrochemicals is falling into disfavor because of the accretion of toxic compounds potentially perilous to humans and the environment. Also, in the increase of resistance of the pathogens and effects on a variety of non-target organisms, they are not considered to be a long-term solution. Therefore, recent efforts have been focused on developing eco-friendly safe, long-lasting, and effective agents against plant pathogens for the management of plant diseases. Endophytic microorganisms have become the center of intensive research because they provide numerous advantages over chemical fertilizers (8). These include environmental protection, safety for humans, reduction of chemical pesticide residues in food, and 
increased biodiversity in a managed ecosystem. Many recent studies have discussed the possible use of microbe-based biocontrol agents as agrochemical substitutes or supplements $(9,10)$. Various bacteria and fungi, such as Streptomyces, Bacillus, Pseudomonas, and Trichoderma as well as nonpathogenic Fusarium respectively, have been successfully used as biocontrol agents $(11,12)$.

Various beneficial bacteria support their host plants by increasing growth and/or by protecting them against pathogenic diseases (13). Among all bacterial communities, actinobacteria, especially Streptomyces have been reported to play an important role in the plant rhizosphere by secreting a wide range of antimicrobial products. Streptomyces characterized by a wide range of modes of action like antibiotic production, lysis of fungal cell walls, competition, and hyper parasitism have been proved to be effective biocontrol agents (14). Besides acting as biocontrol agents, they also possess the potential to stimulate plant growth either directly or indirectly (15). Streptomyces are also known to develop symbiotic associations with crop plants, colonizing their internal tissues without causing disease symptoms and producing phytohormones such as gibberellic acid and indole-3-acetic acid (IAA) $(16,17)$. Indole acetic acid (IAA), one of the most important phytohormones, which has a vital role in the stimulation of root growth. The production of IAA has been reported in various Streptomyces species $(18,19)$. Commercial formulations from Streptomyces have already been successfully developed to control fungal phytopathogens. Mycostop, a Streptomyces- based (Streptomyces griseoviridis K61) biocontrol product, is registered for use in Canada and 15 other countries against Fusarium, Alternaria and Phytophthora. Another product, Actinovate (S. Iydicus WYEC108) is for foliar and soil-borne fungal diseases of greenhouse and field-grown crops (20).

The natural habitat of most Streptomyces is the soil where they may constitute from 1 to $20 \%$ of the culturable population, but Streptomyces are also abundantly present inside plant tissues as endophytes. To discover new biocontrol agents there is a need to screen new Streptomyces strains from untapped sources. Therefore, in the present study an endophytic isolate SP5, exhibiting antifungal and plant growth-promoting activities, was recovered from Citrus jambhiri leaves. The aim of this study was to characterize the isolate SP5 using a polyphasic approach and to assess its in vivo potential for controlling Alternaria solani caused early blight in tomato plants. The strain ability to promote plant growth in vivo was also assessed by observing its impact on various agronomic traits in the tomato plant.

\section{Results}

\section{Isolation and screening}

Total of 42 different endophytic actinobacteria isolates were recovered from plant samples. Among these, 15 isolates demonstrated antifungal activity against one or more test fungi during primary screening, and 9 isolates were found to have antifungal activity in fermentation broth, inhibiting various test fungi to varying degrees. Isolate SP5 was selected for further studies because it exhibiting potent antifungal activity against all the tested phytopathogenic fungi. 


\section{Phenotypic and phylogenetic analysis of Streptomyces sp. SP5}

Streptomyces sp. SP5 showed good growth on SCNA (Starch casein nitrate agar) and all ISP media except ISP2 medium. It exhibited varied cultural characteristics on different media (Table.2).

Pigmentation was not observed in any ISP medium. On SCNA medium strain showed white gray sporulation (Fig.1a) with yellow aerial and substrate mycelia (Fig.1b). In the light microscope (100X), spore chains of SP5 were observed as flexuous spore chains with a hook (Fig.1C) and it was assigned to the Streptomyces retinaculiaperti group (Li et al 2016). SEM micromorphological analysis showed chains of spores on aerial mycelium, each with 20-30 cylindrical spores (1.5-2.0 m length and $1.5 \mathrm{~m}$ width) and a smooth surface (Fig. 1 d). The chemotaxonomic analysis revealed the presence of LL-DAP (LLdiaminopimelic acid) in the cell wall, and no characteristic sugar was detected in whole-cell hydrolysate. In physiological studies, Streptomyces sp. SP5 grew at temperature of $25-45^{\circ} \mathrm{C}$ (optimum at $28{ }^{\circ} \mathrm{C}$ ), pH of 5-10 (optimum at pH 7.0) and showed salt tolerance of up to $5 \%$. In biochemical characteristics, strain SP5 hydrolyzed starch, cellulose, lipid, gelatin, and esculin but not able to hydrolyze casein. Strain SP5 showed positive results for the production of catalase, oxidase, hydrogen sulphide and citrase but gave negative results for both indole production and MRVP (Methyl Red-Voges-Proskauer) test. The strain was able to utilize most of the tested sugars as the sole carbon sources except arabinose (Additional file Table S1). These cultural characteristics showed that SP5 belongs to the genus Streptomyces and was further confirmed by $16 \mathrm{~S}$ rRNA sequencing.

Table.1 Different Streptomyces sp. SP5 antagonist treatments to tomato plants by soil drenching 


\begin{tabular}{|c|c|}
\hline Group Name & Treatments \\
\hline $\begin{array}{c}\text { P } \\
\text { (fungal pathogen) }\end{array}$ & $10 \mathrm{~mL}$ of fungal spore suspension $\left(1 \times 10^{6}\right.$ spores $\left./ \mathrm{mL}\right)$ \\
\hline (control) & water only \\
\hline $\begin{array}{l}\mathrm{CC}+\mathrm{P} \\
\text { (culture cells and pathogen) }\end{array}$ & $\begin{array}{l}10 \mathrm{~mL} \text { of fungal spore suspension }\left(1 \times 10^{6} \text { spores } / \mathrm{ml}\right) \text { and } 10 \mathrm{~mL} \text { of } \\
\text { Streptomyces sp. SP5 culture cell suspension }\left(1 \times 10^{6} \text { cells } / \mathrm{mL}\right)\end{array}$ \\
\hline $\begin{array}{c}\text { CS }+ \text { P } \\
\text { (culture supernatant and } \\
\text { pathogen) }\end{array}$ & $\begin{array}{l}10 \mathrm{~mL} \text { of fungal spore suspension }\left(1 \times 10^{6} \text { spores } / \mathrm{mL}\right) \text { and } 10 \mathrm{~mL} \text { of culture } \\
\text { supernatant of Streptomyces sp. SP5 }\end{array}$ \\
\hline \multicolumn{2}{|l|}{$\begin{array}{c}\text { (solvent extract and } \\
\text { pathogen) }\end{array}$} \\
\hline \multicolumn{2}{|l|}{$\begin{array}{c}\text { (culture precipitates and } \\
\text { pathogen) }\end{array}$} \\
\hline $\mathrm{CC}$ & $10 \mathrm{~mL}$ of Streptomyces sp. SP5 culture cell suspension $\left(1 \times 10^{6}\right.$ cells $\left./ \mathrm{mL}\right)$ \\
\hline \multicolumn{2}{|l|}{ (culture cells) } \\
\hline CS & $10 \mathrm{~mL}$ of culture supernatant of Streptomyces sp. SP5 \\
\hline \multicolumn{2}{|l|}{ (culture supernatant) } \\
\hline SE & $10 \mathrm{~mL}$ of solvent extract of Streptomyces sp. SP5 $(1 \mathrm{mg} / \mathrm{mL})$ \\
\hline \multicolumn{2}{|l|}{ (solvent extract) } \\
\hline AP & $10 \mathrm{~mL}$ acetone precipitate $(250 \mu \mathrm{g} / \mathrm{mL})$ \\
\hline (Acetone precipitate) & \\
\hline
\end{tabular}

\section{Table 2: Streptomyces sp. SP5 cultural characteristics of on various ISP media}

\begin{tabular}{|llllll|}
\hline Medium & Sporulation & $\begin{array}{l}\text { Substrate } \\
\text { Mycelium }\end{array}$ & $\begin{array}{l}\text { Aerial } \\
\text { Mycelium }\end{array}$ & Growth & Pigmentation \\
\hline ISP1 & White & Yellow & Yellow & Good & - \\
\hline ISP2 & - & Yellow & - & Poor & - \\
\hline ISP3 & Grey & Light brown & Brown & Very good & - \\
\hline ISP4 & White & Creamish & Brown & Very good & - \\
\hline ISP5 & Grey & Light brown & Dark brown & Good & - \\
\hline ISP6 & White & Pale yellow & Yellow & Good & - \\
\hline ISP7 & Grey & Light grey & Pale yellow & Good & - \\
\hline
\end{tabular}




\section{Identification and phylogenetic analysis of Streptomyces sp. SP5}

Almost complete sequence (1400bp) of the 16rRNA gene of Streptomyces sp. SP5 was determined and aligned, using the EzTaxon database. The 16S rRNA gene sequence of Streptomyces sp. SP5 has been deposited in the GenBank database with the accession number MW564023. Nucleotide BLAST search analysis showed $100 \%$ pairwise similarity with Streptomyces plicatus NBRC 13071, Streptomyces enissocaesilis NRRL B- 16365 and Streptomyces rochei NRRL B- 2410. Streptomyces SP5 formed a clade with Streptomyces vinaceusdrappus in a phylogenetic tree constructed using neighbor-joining method with a low bootstrap value of $22 \%$ ( $(50 \%)$ (Additional file Fig. S1). However, in the maximum parsimony tree Streptomyces sp. SP5 formed a different clade among Streptomyces with a bootstrap value of $10 \%$ and formed the sister species to a clade containing Streptomyces plicatus NRBC 13071 (AB184291), Streptomyces enissocaesilis NRRL B-16365 (DQ026641), S. vinaceusdrappus NRRL 2363 (AY999929) (Fig.2). This excluded specific relatedness of Streptomyces sp. SP5 to the species with which it showed the maximum i.e100\% sequence similarity. Thus, based on phylogenetic analysis, strain SP5 can be designated as a new species of Streptomyces but to confirm further DNA-DNA hybridization with closely related species is required. The Streptomyces sp. SP5 strain has been deposited in International Depository Authority (MTCC and Gene Bank, CSIR-IMTECH, Chandigarh (India), with the accession number is MTCC-13071.

\section{Antifungal potential}

Streptomyces sp. SP5 showed antifungal activity against all the tested fungal phytopathogens. The production of active metabolites in SCN culture broth against fungal pathogens was detected after $48 \mathrm{~h}$ of incubation, maximum activity was reached after 120 hours, and then began to decrease as the incubation period was extended further. Additionally, during the 10-day activity profile, there was a positive correlation between antifungal activity and biomass (Fig.3). The maximum biomass was obtained after the fifth day of incubation, which coincided with the maximum activity obtained on the same day. In vitro bioassay demonstrated broad-spectrum antifungal activity of Streptomyces sp. SP5 against tested strains (Fig.4). Among the tested fungi, higher activity was observed against $F$. oxysporum, C. herbarum, F. moniliforme (25-28mm) as compared to A. brassicicola, A. alternata, $C$. acutatum, A. solani, and F. solani (20-25mm).

\section{Active metabolite extraction}

The active metabolites from culture supernatant were extracted in diethyl ether. After the concentration of the organic phase using rotavapor, a light-yellow colored crude extract was obtained, which was redissolved in chloroform. Diethyl ether solvent extract showed pronounced activity against phytopathogen A. brassicicola, A. solani, F. oxysporum, F. solani $(15-20 \mathrm{~mm})$. However, the activity was also observed in the aqueous phase which indicated that the bioactive compounds were not fully recovered by solvent extraction. Therefore, another technique i.e., Acetone precipitation was employed to recover the bioactive metabolites from the culture supernatant. The active metabolites through 
precipitation showed antifungal activity against $A$. brassicicola, $A$. solani, $C$. acutatum, F. oxysporum, $F$. solani, and C. herbarum (20-30mm).

\section{Stability of active metabolites in the culture supernatant}

The stability of metabolites present in the culture supernatant was investigated under various physical stresses. Active metabolites remained completely stable at $37^{\circ} \mathrm{C}$ after $1 \mathrm{~h}$ exposure. However, a loss of 20,48 , and $68 \%$ in the residual activity was observed at $70^{\circ} \mathrm{C}, 100^{\circ} \mathrm{C}$, and autoclaving $\left(121^{\circ} \mathrm{C}\right.$ for 20 $\mathrm{min}$ ), respectively. The metabolites remained active at extreme pH values (from 2 to 14) with 92 and $84 \%$ residual activity, respectively. The metabolites were photostable in both UV and sunlight (Table.3).

Table 3: Effect of various parameter on antifungal activity of culture supernatant against $A$. solani.

\begin{tabular}{|c|c|c|}
\hline \multirow[t]{3}{*}{ Treatment } & \multicolumn{2}{|l|}{ Streptomyces sp. SP5 } \\
\hline & Zone of inhibition (mm) & \% Residual activity \\
\hline & against $A$. solani & \\
\hline Control (Untreated) & $25 \pm 0.0$ & 100 \\
\hline \multicolumn{3}{|c|}{ Temperature treatment } \\
\hline $37^{\circ} \mathrm{C}, 1 \mathrm{~h}$ & $25.0 \pm 0.2$ & 100 \\
\hline $50^{\circ} \mathrm{C}, 1 \mathrm{~h}$ & $23.0 \pm 0.4$ & 92 \\
\hline $70^{\circ} \mathrm{C}, 1 \mathrm{~h}$ & $20.0 \pm 1.0$ & 80 \\
\hline $100^{\circ} \mathrm{C}, 1 \mathrm{~h}$ & $13.0 \pm 0.3$ & 52 \\
\hline $121^{\circ} \mathrm{C}, 45 \mathrm{~min}$ & $8.0 \pm 0.1$ & 32 \\
\hline$-20^{\circ} \mathrm{C}, 1 \mathrm{~h}$ & $25.0 \pm 0.0$ & 100 \\
\hline \multicolumn{3}{|l|}{ pH tolerance } \\
\hline $\mathrm{pH} 2$ & $22.0 \pm 0.3$ & 88 \\
\hline $\mathrm{pH} 14$ & $23.0 \pm 0.1$ & 92 \\
\hline \multicolumn{3}{|l|}{ Photostability } \\
\hline Sunlight, $1 \mathrm{~h}$ & $25.0 \pm 0.3$ & 100 \\
\hline UV light, $1 \mathrm{~h}$ & $25.0 \pm 0.1$ & 100 \\
\hline
\end{tabular}

\section{Plant growth-promoting potential}


Streptomyces sp. SP5 produced $40 \mu \mathrm{g} / \mathrm{ml}$ indole acetic acid in an initial screening for indole acetic acid production. TLC and HPLC analysis demonstrated the ability of strain Streptomyces sp. SP5 to produce IAA. The ethyl acetate crude extract displayed a clear pink-colored spot on the TLC plate after being treated with salkowski regent at $\mathrm{Rf}$ value corresponding to standard IAA (0.9). After the detection of IAA in TLC, partial purification of crude extract containing IAA was done using silica gel chromatography. HPLC analysis was used to precisely classify and quantify the IAA production. The partially purified extract and corresponding reference authentic standard both displayed peaks at the same retention time (18.6 min) as shown in Fig.5. Experiments were carried out with different values of the incubation period, temperature, $\mathrm{pH}$, and L-tryptophan concentration for the highest IAA production by Streptomyces SP5. The effect of the incubation period, as shown in (Fig.6a), showed that IAA production began within 24 hours, increased steadily over time, reached a maximum of $58.43 \mu \mathrm{g} / \mathrm{ml}$ after 6 days, then began to decline with additional incubation, reaching $5.45 \mu \mathrm{g} / \mathrm{ml}$ after 10 days. Within the $\mathrm{pH}$ range 4 to 10 , the impact of $\mathrm{pH}$ on IAA production was investigated. The data in Fig.6b show the effect of $\mathrm{pH}$ on IAA production. Streptomyces SP5 produced the maximum IAA of $65.32 \mu \mathrm{g} / \mathrm{ml}$ at an initial pH of 7.0. Acidity and high alkalinity of the medium led to a marked decrease in growth and IAA production. Incubation temperature had a significant impact on IAA production. At $28^{\circ} \mathrm{C}$, the maximum production of 58.63 $\mu \mathrm{g} / \mathrm{ml}$ IAA was achieved (Fig.6c). The effect of L-tryptophan concentration on IAA production were also investigated, and it was discovered that in the absence of L-tryptophan i.e. IAA precursor, the strain was unable to produce IAA. With the increase in concentrations of L-tryptophan from 0 to $5 \mathrm{mg} / \mathrm{ml}$, there was an increase in the production, and the maximum biosynthesis of $99.65 \mu \mathrm{g} / \mathrm{ml} \mathrm{IAA}$ was achieved at a concentration of $5 \mathrm{mg} / \mathrm{ml} \mathrm{L-tryptophan} \mathrm{(Fig.6d).} \mathrm{IAA} \mathrm{production} \mathrm{decreased} \mathrm{slightly} \mathrm{with} \mathrm{higher} \mathrm{L-}$ tryptophan concentrations. Additionally, a positive correlation between IAA production and biomass was observed with optimization parameters.

\section{Streptomyces sp. SP5 In vivo biocontrol of early blight diseases by and its impact on tomato plant growth promotion}

Fig. 7 showed the in vivo biocontrol potential of Streptomyces sp. SP5 against Alternaria solani on tomato plants. Plants treated with Streptomyces sp. SP5 antagonists (culture cells/culture supernatant/solvent extract/ acetone precipitates) showed no symptoms of early blight disease throughout the 3 months of experiment whereas negative control (plants treated with pathogen only) having the symptoms of early blight disease i.e., leaf blight (Fig. 8). Leaf blight on the negative control plants were observed after one month of experiments and at the end of experiment plants were defoliated. Whereas the plants treated with Streptomyces sp. SP5 antagonists not only control the $100 \%$ diseases incidence but also increased the various agronomic traits viz. shoot length $(120-202.35 \%)$, root length (432 - 516.12\%), fresh weight of shoot (135.48 - 270.09\%), fresh weight of root (243.05 $428.30 \%)$, dry weight of shoot (644.98 - 1346.99\%) and dry weight of root (1332.4 - 2467.5\%) over the fungal pathogen treated plants. Among the four treatments, acetone precipitates and culture cells were found to be more effective to enhance plant development as compared to the culture supernatant and solvent extract. Additionally, in the absence of pathogen stress, Streptomyces sp. SP5 antagonists showed plant growth promotion by significantly increasing shoot length (71.875 to $108.54 \%$ ), root length 
(76.82 to $131.70 \%$ ), fresh weight of shoot (42.85 to $115.63 \%$ ), fresh weight of root (74.15 to $264.23 \%$ ), dry weight of shoot (100.98 to $264.23 \%$ ) and dry weight of root (265.90 to $538.63 \%)$ over the control plants (Additional file Table S2, Fig: 8, 9). During the period of an experimental study, early flowering and fruiting were also observed in plants treated with antagonists (culture cells/protein precipitates) both in the presence and absence of pathogen stress whereas no such stages were observed in control and pathogen infested plants. The data indicated the biocontrol and plant growth-promoting potential of Streptomyces SP5 and its metabolites.

\section{Discussion}

Fungal phytopathogens pose a significant threat to current agricultural systems around the world, since they are responsible for significant drop agricultural yield globally. Despite attempts to tackle them through the use of resistant crop varieties, chemical pesticides, and various other agricultural practices, there is widespread concern about public health and environment protection as a result of the harmful effect of agrochemicals $(30,31)$. Thus, greater emphasis must be laid on controlling the phytopathogens by natural means. Therefore, there has been an increasing interest in the isolation of agriculturally important microbes from rare and scanty sources for their exploitation in biological control and plant growth promotion (32). Among microbes, actinobacteria, especially Streptomyces produce major bioactive metabolites which exert positively antagonistic effects on a wide range of plant pathogenic fungi (33-36). Their filamentous and sporulating properties enable them to thrive in threatening environments (37). Agriculturally important antibiotics such as blasticidin $\mathrm{S}$, kasugamycin, polyoxins, and validamycin A have been explored as commercial biological control agents from Streptomyces spp. (38). As actinobacteria are well known excellent source of bioactive compounds, it is predicted that such organisms from unique habitats may prove useful for this purpose, and one such habitat could be the plant endosphere. Researcher isolated endophytic actinobacteria from different plants and are thought to be new sources of various bioactive compounds that can be used to fight pathogenic microorganisms (39-42). Multiple reports have described the isolation of Streptomyces from plant roots followed by stems and leave exhibits antifungal and plant growth-promoting activities $(43,44)$.

In this research study, a Streptomyces sp., designated as Streptomyces sp. SP5, was isolated from leaves of Citrus jambhiri, and characterized through a polyphasic approach. The Streptomyces sp. SP5 flexuous spore chains, as well as chemotaxonomical markers (LL-DAP in cell wall and no characteristic sugar in whole cell hydrolysate), indicated that it belonged to the Streptomyces genus. In phylogenetic characterization, Streptomyces sp. SP5 displayed 100\% sequence similarity with S. plicatus NBRC 13071, S. enissocaesilis NRRL B- 16365 and S. rochei NRRL B- 2410. However, formation of distinct clade among Streptomyces and low bootstrap values of $22 \%, 10 \%$ in phylogenetic trees constructed using neighbors joining and maximum parsimony method respectively indicated its unrelatedness with the most similar Streptomyces spp., and might be designated as a new sp. of Streptomyces. However, to ensure Streptomyces sp. SP5 as novel species further DNA-DNA hybridization with closely related species is required. In recent times, Sahu et al. (45) reported a novel sp. of Allostreptomyces which showed $99.0 \%$ nucleotide sequence similarity and $100 \%$ bootstrap value with the type strain Allostreptomyces 
psammosilenae. But DNA-DNA hybridization with closely related species showed only $54.5 \%$ relatedness with the type strain, which proved the novelty of this sp. as Allostreptomyces indica sp. nov.

Streptomyces sp. SP5 inhibited various phytopathogenic fungi (F. moniliforme, A. brassicicola, $C$. herbarum, $A$. solani, F. solani, $C$. acutatum) to varying degrees. The test pathogen may play a role in the variation in antagonistic behaviour. The genus Streptomyces has been studied broadly in the past decades and reported for the production of antifungal compounds (46-49). Since the biocontrol agents' shelf-life is dependent on environmental conditions such as soil temperature, soil pH, nutrient availability and water status, one of the major issues in the commercialization of biocontrol agents is their loss of viability over time (50). However, antifungal metabolites produced by Streptomyces sp.SP5 was found to be photo-thermostable and $\mathrm{pH}$ stable. These characteristics of metabolites make them suitable for the development of effective biocontrol agents for varied climate conditions throughout the globe.

The Streptomyces sp. SP5 also exhibited plant growth-promoting activity by synthesizing indole acetic acid (IAA). It is one of the most physiologically active auxins which stimulate and facilitate plant growth (51-53). Although several studies have reported IAA production in soil-dwelling Streptomyces spp. (52, $54,55)$ and biosynthesis of IAA by endophytic Streptomyces (56-57). Streptomyces sp. SP5 has been found to produce a significant amount $\left(40 \mu \mathrm{g} \mathrm{ml}^{-1}\right)$ of phytohormone IAA when grow $n$ in YMB broth supplemented with tryptophan. TLC analysis revealed identical Rf value with IAA standards which is inconsistent with previous studies (52). HPLC is a reliable method for the identification of auxins thus characterization of IAA was performed by using HPLC. The retention times of partially purified peak of the extract was comparable to those of authentic IAA standard, confirming IAA production by Streptomyces sp. SP5. Results of the classical optimization experiment showed that the incubation time, temperature, and $\mathrm{pH}$ played an important role in IAA production which is in agreement with other reports $(58,59)$. Plantassociated microbes synthesized IAA via tryptophan (trp)-dependent and -independent pathway (60). IAA production from Streptomyces sp. SP5 increased two-folds in the presence of L-tryptophan which strongly indicated that Streptomyces sp. SP5 synthesized IAA via the tryptophan-dependent pathway. It was also observed that beyond optimized concentrations of tryptophan IAA production were adversely affected in Streptomyces sp. SP5. Myo (52) also reported that higher tryptophan concentration affects the capability of strain to produce IAA. Manulis (61) have reported that various Streptomyces spp. including S. violaceus, S. griseus, S. scabies, S. coelicolor S. exfoliatus, and S. lividans, produce indole- 3acetic acid (IAA) when grown in the presence of tryptophan.

It is a common knowledge that a strain ability to suppress disease in vitro does not imply that it can be used in the fields as biocontrol agents since the strains might not be able to demonstrate their potential in natural conditions (62). Therefore, in this study, in vivo pot experiments were conducted against the early blight of tomato caused by Alternaria solani to explore the possibility of using Streptomyces sp. SP5, a biocontrol agent under natural conditions. Several Streptomyces spp. and their bioactive compounds have been reported as biocontrol agents, effective against numerous plant pathogens (63-65). The results of the present study revealed a remarkable effect of Streptomyces sp. SP5 in mitigating early blight stress in tomato plants. The treatment of soil, infested by A. solani, with Streptomyces sp. SP5 
cells/supernatant/solvent extract and acetone precipitates exhibited a significant increase in various growth traits of tomato plants and disease suppression in comparison to the plants infested with pathogen only. To the best of our knowledge, only a few reports are available in the literature pertaining to in vivo biocontrol of early blight (66-69). The data obtained from the in vivo experimental study suggested the superiority of Streptomyces SP5 over the earlier reported studies to control early blight of tomato. Khan (69) demonstrated the potential of Paenibacillus lentimorbus B-30488 ${ }^{\mathrm{r}}$ to control early blight and reported that treatment of pathogen-infected plants with P. lentimorbus B-30488 ${ }^{r}$ exhibited $16 \%$ defoliation and increased the shoot length (23.3\%), fresh plant weight (151.02), dry plant weight (51.64\%) whereas no effect on root length. On the other hand, in our study Streptomyces sp. SP5 completely suppressed the early blight with $0 \%$ defoliation and no disease symptoms appeared in treated plants while complete defoliation was observed in plants exposed to the pathogen. Additionally, Streptomyces sp. SP5 significantly enhanced shoot length (202.35\%), root length (516.12\%), fresh weight of shoot $(270.09 \%)$, fresh weight of root $(428.30 \%)$, dry weight of shoot $(346.99 \%)$, and dry weight of root (2467.5\%). Similarly, Cuppels (68) evaluated efficacy of strains S. griseoviridis K61 and S. lydicus WYEC108 isolated from the formulated commercial products Mycostop and Actinovate, respectively to control early blight, anthracnose and bacterial spot of field tomatoes. Both BCAs strongly suppressed the growth of $A$. solani in dual culture agar diffusion bioassay. S. griseoviridis successfully controlled anthracnose and early blight diseases whether applied before pathogen or simultaneously with the pathogen but $S$. lydicus provided protection only when applied $48 \mathrm{~h}$ before the exposer pathogen.

Moreover, during the pot trial Streptomyces sp. SP5 also significantly increased various growth parameters of the tomato plants such as shoot and root length in the absence of pathogen stress. These findings support previous research that found Streptomyces spp. not only protected plants from pathogens, but also enhanced plant growth and physiology (63, 70-72). Dias (71) observed a significant increase in shoot length $(1.7 \%-31.89 \%)$ and root length $(49.15 \%-88.13 \%)$ of tomato plants treated with different Streptomyces isolates. In our previous studies, we reported Streptomyces sp. MR14, the cells and metabolites of which significantly enhanced various plant growth traits i.e. shoot length (32.36\%), root length (59.88), shoot fresh weight (67.65), root fresh weight (73.97), shoot dry weight (50\%) and root dry weight (116.88) in tomato plants (63). However, Streptomyces sp. SP5 reported in the present study showed highly pronounced effect on various plant growth parameters and increased shoot length, root length, shoot fresh weight, root fresh weight, shoot dry weight and root dry weight by $108.59 \%, 131.70 \%$, $115.63 \%, 210.95 \%, 264.23 \%$ and $538.63 \%$, respectively in tomato plants.

\section{Conclusion}

The results of in vitro and in vivo studies are highly significant and data reveals that Streptomyces sp. SP5 is superior to the previously reported Streptomyces spp. and might be used as a potential biological agent to control fungal phytopathogens and as an effective biofertilizer to promote plant growth.

\section{Material And Methods}




\section{Sample collection}

Leaves and roots of healthy plants (Cinnamon basil, Ricinus communis, Epipremunum aureum, Citrus jambhiri, Hibiscus rosasinensis were collected from "Botanical Garden" of Guru Nanak Dev University, Amritsar, Punjab, India ( $31^{\circ} 37^{\prime} 45^{\prime \prime} \mathrm{N}$ and $\left.74^{\circ} 49^{\prime} 36^{\prime \prime} \mathrm{N}\right)$. Plant samples were wrapped aseptically in plastic bags and taken to the laboratory where they were processed within 4 hours.

\section{Test organisms}

Different test phytopathogenic fungi viz. Alternaria brassicicola (MTCC2102), Alternaria solani (MTCC2101), Colletotrichum acutatum (MTCC1037), Fusarium oxysporum (MTCC284), Cladosporium herbarum (MTCC351), were procured from Microbial Type Culture Collection (MTCC), CSIRInstitute of Microbial Technology (IMTECH), Chandigarh, India. Whereas, Fusarium solani (NFCCI 91) was obtained from the National Fungal Culture Collection of India NFCCl, Pune. Fusarium moniliforme and Alternaria alternata were isolated in the lab and all of the fungal cultures were maintained at $4^{\circ} \mathrm{C}$ on Potato dextrose agar (PDA).

\section{Isolation of endophytic strains from plant samples}

The collected plant samples were washed under running tap water for 1-2 minutes to remove soil particles. The samples were then surface sterilized by $70 \%$ ethanol for 10 min followed by treatment with $1 \%$ sodium hypochlorite solution for $15 \mathrm{~min}$ (21). Plant samples were then repeatedly washed with sterilized water, air-dried in a laminar airflow hood, and cut into small pieces using a sterile razor blade. The small pieces of sterile samples were placed on SCNA medium (starch casein nitrate agar). To inhibit the growth of fungi and other non-Streptomyces bacteria, cycloheximide $(50 \mathrm{~g} / \mathrm{ml})$ and nalidixic acid $(50 \mathrm{~g} / \mathrm{ml})$ were added to the medium. The plates were then incubated at $28^{\circ} \mathrm{C}$ for $7-21$ days. Isolated actinobacteria colonies were subcultured and purified on SCNA plates. Isolate spores were reserved as a stock in $20 \%$ glycerol at $-20^{\circ} \mathrm{C}$ for potential use.

\section{Screening and selection of the isolate}

Primary screening determines the ability of the microorganisms to produce an antifungal metabolite without providing a significant idea about the production potential of the organism. Modified Kirby Bauer antibiotic susceptibility test was used for primary screening (22). The actinobacterial isolates were cultured for seven days on the SCNA medium at $28^{\circ} \mathrm{C}$. Six mm agar discs from well-grown culture of actinobacterial isolates were placed on PDA plates which were already seeded with the test phytopathogenic fungi $\left(100 \mu \mathrm{l}\right.$ of $10^{6}$ spore $\left.\mathrm{ml}^{-1}\right)$. The plates were then kept at $4^{\circ} \mathrm{C}$ for $30 \mathrm{~min}$ for the diffusion and then incubated at $28^{\circ} \mathrm{C}$. The zone of inhibition was determined after $48 \mathrm{~h}$.

Following primary screening, the active isolates were subjected to secondary screening. Three discs of actinobacterial culture with a diameter of $6 \mathrm{~mm}$ were transferred to $250 \mathrm{ml}$ Erlenmeyer flasks containing $50 \mathrm{ml}$ of starch casein nitrate broth and incubated for 10 days at $28^{\circ} \mathrm{C}$ in a rotary shaker at $180 \mathrm{rpm}$. 
Mycelia were extracted by centrifuging at $10,000 \mathrm{~g}$ for 20 minutes at $4^{\circ} \mathrm{C}$ and the supernatant was used for bioassay. The PDA plates inoculated with test fungi $\left(100 \mu \mathrm{l}\right.$ of $10^{6}$ spore $\left.\mathrm{ml}^{-1}\right)$ were punctured with sterile cork borer to create wells ( $6 \mathrm{~mm}$ in diameter) and $200 \mu \mathrm{l}$ of culture supernatant was transferred to each well under aseptic conditions. The plates were incubated at $28{ }^{\circ} \mathrm{C}$ for three days and observed for antifungal activity of the isolates as clear zones of inhibition (in $\mathrm{mm}$ ) around well. Out of 9 isolates from secondary screening, isolate SP5 was selected for further studies based on its broad-spectrum antifungal activity.

\section{Morphological, physiological, and biochemical characterization of Streptomyces sp. SP5}

Cultural characteristics were determined as per methods described by Shirling and Gottlieb (23) in the International Streptomyces Project (ISP). Bright light microscopy and electron microscopy were used to examine the strain morphological characteristic. Physiological and biochemical characterization such as growth at different temperatures $\left(20-50^{\circ} \mathrm{C}\right), \mathrm{pH}(5.0-12.0)$, salt concentration $(0-20 \% \mathrm{w} / \mathrm{v})$, and capacity to generate different hydrolytic enzymes were carried out according standard protocols (24). According to Shirling and Gottlieb (1966), sugars assimilation as carbon source was investigated. The major diagnostic features of Streptomyces, a sugar pattern in whole-cell hydrolysate and an isomer of diaminopimelic acid (DAP) in the cell wall, were determined using Lechevalier and Lechevalier (1980).

\section{Genomic characterization}

The genomic DNA of the isolate was extracted using Marmur (26) method for 16S rRNA gene sequencing. The 16S rRNA gene sequence was amplified by polymerase chain reaction (PCR) using primers $27 f$ (5'-AGAGTTTGATCC TGGCTCAG-3') and 1492r (5'-AGAAAGGAGGTGATC CAGGC-3'). Amplification was done for 40 cycles in an PCR machine (Eppendorf-gradient). Each cycle included a denaturation stage of 1 minute at $94{ }^{\circ} \mathrm{C}$, an annealing step of 1 minute at $50{ }^{\circ} \mathrm{C}$, and an extension step of 2 minutes at $72{ }^{\circ} \mathrm{C}$ and a final extension of 10 minutes at $72{ }^{\circ} \mathrm{C}$. The QIA quick gel extraction kit (Qiagen, Germany) was used to purify the obtained PCR product. The Institute of Microbial Technology (IMTECH), Chandigarh, India, sequenced the 16S rRNA gene of Streptomyces sp. SP5. For the detection of phylogenetic neighbors and calculation of pairwise 16S rRNA gene sequence similarities, the EzTaxon server (http://www.ezbiocloud.net) was used (27). The Clustal W program was used to align the nearly complete sequence (1400 bp). Phylogenetic trees based on bootstrap values (1000 replications with MEGA6 software) were constructed using neighbor-joining and maximum-parsimony methods (28-29).

\section{Time course experiment related to antifungal metabolites production and growth}

For antifungal profiling determination, seed culture was prepared, three discs ( $6 \mathrm{~mm}$ diameter) of 7 days old Streptomyces sp. SP5 culture were inoculated into Erlenmeyer flasks $(250 \mathrm{ml})$ containing $50 \mathrm{ml}$ of starch casein nitrate broth and incubated at $28^{\circ} \mathrm{C}$ at $180 \mathrm{rpm}$ for a week. Inoculating the production medium (SCN broth) with seed culture ( $2 \%$ ) and incubating at $28{ }^{\circ} \mathrm{C}$ for 10 days with agitation at $180 \mathrm{rpm}$ was used for fermentation. After every 24 hours, the flasks were harvested, and the culture broth was centrifuged at $10,000 \mathrm{~g}$ for 10 minutes to remove the biomass. The biomass was dried for 2 days at $60^{\circ} \mathrm{C}$ 
and measured (mg). The activity against test fungal phytopathogens was determined using the remaining cell-free culture supernatant. The test fungi $\left(100 \mu \mathrm{l}\right.$ of $10^{6}$ spore $\left.\mathrm{ml}^{-1}\right)$ were seeded on PDA, which were punctured with sterile cork borer to create $6 \mathrm{~mm}$ wells. The plates were held in the refrigerator for 1 hour after adding $200 \mu \mathrm{l}$ of culture supernatant to allow active metabolites to diffuse. After diffusion, the plates were incubated at $28^{\circ} \mathrm{C}$ for $4-5$ days. The antifungal activity of the isolate was measured in millimetres as zones of inhibition around wells.

\section{Recovery of antifungal metabolites}

For the production of antifungal active metabolites, fermentation was carried out by inoculating the strain (at a concentration of $2.5 \%$ from seed culture) in a production medium and incubating for five days at $28^{\circ} \mathrm{C}$ under shaking $(180 \mathrm{rpm})$. Fermentation was terminated when the maximum antifungal activity was observed (5th day) and culture broth was centrifuged at $10,000 \mathrm{~g}$ at $4^{\circ} \mathrm{C}$ for $10 \mathrm{~min}$ to separate the mycelium.

The active metabolites from culture supernatant were recovered by solvent extraction. Different organic solvents (hexane, diethyl ether, chloroform, ethyl acetate, butanol) having a wide range of polarity were screened to work out the best extractant. The supernatant of Streptomyces sp. SP5 was extracted twice in the ratio of 1:1 (supernatant: solvent). Rotavapor (BUCHI Rotavapor R-210) was used to concentrate the obtained organic phase to dryness. The obtained crude extracts were redissolved in methanol $(1 \mathrm{ml})$ and tested for antifungal activity against test strains. Acetone precipitation was also employed to extract out the antifungal metabolites from the culture supernatant. For acetone precipitation, two volumes of $100 \%$ chilled acetone were added to the culture supernatant and kept for 1 hour. at $-20^{\circ} \mathrm{C}$. The precipitates were recovered by centrifugation at $10,000 \mathrm{rpm}$ for 10 minutes at $4^{\circ} \mathrm{C}$, and were redissolved in distilled water. The antifungal activity of precipitates was determined against different test phytopathogenic fungi using the agar well diffusion method.

\section{Stability of active metabolites in the culture supernatant}

The supernatant was heated at various temperatures $\left(3{ }^{\circ} \mathrm{C}, 50{ }^{\circ} \mathrm{C}, 70{ }^{\circ} \mathrm{C}, 100{ }^{\circ} \mathrm{C}\right.$ and autoclaving at 121 ${ }^{0} \mathrm{C}$ ) for $1 \mathrm{hr}$, and was also exposed to a lower temperature $\left(-2{ }^{\circ} \mathrm{C}\right)$ for one hour to determine thermostability. The effect of $\mathrm{pH}$ on activity was determined by adjusting the $\mathrm{pH}$ from 2 to 14 , followed by incubation for one $\mathrm{h}$ at $28^{\circ} \mathrm{C}$. Photostability was tested by exposing the supernatant separately to UV $(200-600 \mathrm{~nm})$ and sunlight $(1 \mathrm{hr})$. The antifungal activity of all the treated samples was then tested using a well diffusion assay.

\section{Plant growth promoting potential}

\section{Indole acetic acid (IAA) production}

For Indole acetic acid (IAA) production $50 \mathrm{ml}$ of yeast malt broth (YMB; g/lt: yeast extract 4.0, malt extract 10.0, dextrose 4.0) containing $0.2 \%$ L-tryptophan was inoculated with three plugs $(6 \mathrm{~mm})$ of seven-day-old 
Streptomyces sp. SP 5 culture and then incubated at $28^{\circ} \mathrm{C}$ for 7 days under shaking (180rpm). After incubation, the broth was centrifuged at $10,000 \mathrm{~g}$ for 15 minutes to remove mycelia. After centrifugation $2 \mathrm{ml}$ Salkowski reagent, as modified by Gordon et al (1950) was added into tubes containing $1 \mathrm{ml}$ of cellfree supernatant and incubated for $25 \mathrm{~min}$ at room temperature. The developed pink color intensity measured at $530 \mathrm{~nm}$, which indicates indole acetic acid production. The concentration of IAA produced was estimated against the standard curve of IAA using a concentration range of $10-100 \mu \mathrm{g} / \mathrm{ml}$.

\section{Extraction, purification, and identification of Indole acetic acid}

The culture supernatant was acidified to $\mathrm{pH} 2.5$ with $\mathrm{HCl}$ and extracted twice with ethyl acetate using solvent-solvent extraction. The separated organic phase was concentrated using a rotary evaporator and redissolved in ethyl acetate $(1 \mathrm{ml})$. For IAA analysis, the ethyl acetate extract was separated using thinlayer chromatography (TLC) with propanol: water (8:2, v/v) as solvent system, and the chromatogram was observed after spraying the plates with Salkowski regent. IAA was partially purified from the crude solvent extract by using silica gel column chromatography and fractions were collected with the solvent system of ethyl acetate and hexane $(20: 80 \mathrm{v} / \mathrm{v})$. Each fraction was checked for the presence of IAA by TLC using Salkowski regent. The indole containing fraction was further quantified by high-performance liquid chromatography (HPLC) using C-18 reversed-phase column eluting with methanol: $1 \%$ acetic acid in water (40:60 v/v as mobile phase) at $1 \mathrm{ml} \mathrm{min}^{-1}$ flow rate. The pure IAA compound was spiked into the column as standard and from partially purified IAA extract $20 \mu \mathrm{l}$ aliquot was analyzed. The identical retention time of the respective standard was used to assess the presence of IAA in the specimens.

\section{Optimization of IAA production}

Various factors such as incubation period, $\mathrm{pH}$, temperature, and tryptophan concentration were studied using one variable at a time approach or classical approach to optimise IAA production. The effect of incubation time on IAA synthesis was investigated by growing the culture in yeast malt broth for 10 days and IAA production was checked after every $24 \mathrm{~h}$. The optimal for production was determined by changing the initial $\mathrm{pH}$ of the medium from 2-10 using $1 \mathrm{~N} \mathrm{HCl}$ and $1 \mathrm{~N} \mathrm{NaOH}$. Similarly, the effect temperature of incubation on IAA production was investigated by incubating Streptomyces sp. SP5 into the same medium at $20,25,28,30,35$, and $40^{\circ} \mathrm{C}$ for six days. The effect of L-tryptophan concentration was calculated by adding $0,1,2,3,4$, and $5 \mathrm{mg} / \mathrm{ml}$ of L-tryptophan to medium ( $\mathrm{pH} 7.0)$ and incubating for six days. The bacterial growth rate was measured, culture broth was centrifuged at $10,000 \mathrm{~g}$ for $10 \mathrm{~min}$ and the biomass was dried at $60^{\circ} \mathrm{C}$ for 2 days and weighed $(\mathrm{mg})$. All experimentations were performed in triplicates and average values were observed.

\section{Streptomyces sp. SP5 In vivo biocontrol of Alternaria solani and its effect on tomato plant growth promotion}

Efficacy of Streptomyces sp. SP5 against early blight disease was tested by conducting three independent pot trials at Guru Nanak Dev University (Amritsar) using soil drenching method. The aim was to see whether Streptomyces sp. SP5 culture cells, culture supernatant, solvent extract as well as acetone 
precipitates could regulate Alternaria solani (the causal fungal phytopathogen of early blight in tomato) and promote various plant growth traits. Tomato seeds susceptible to Alternaria solani (Solanum lycopersicum Mill. "Pusa Ruby") were sown in sterile soil for 3 weeks at $28 \pm 2.0^{\circ} \mathrm{C}$ and after true leaf stage, a single plant was transplanted into a pot of $8 \mathrm{~cm}$ diameter containing $100 \mathrm{~g}$ sterile soil for each treatment. The plants were subjected to a variety of treatments by Streptomyces sp. SP5 antagonists viz. Streptomyces sp. SP5 cells, supernatant, solvent extract and Acetone precipitates, with and without pathogen (Table.1). Three replications were maintained for each treatment and the pots were kept under natural conditions (temperature $22 \pm 2.0^{\circ} \mathrm{C}$, photoperiod L16: D8). Plants were watered and disease symptoms, flowering, and fruiting stages were observed daily. After disease appearance in the control plants, all treated plants were uprooted carefully, and plants were washed with running tap water to remove the adhered soil, shoot \& root length, and fresh \& dry weights of tomato seedlings were recorded. Data obtained from in vivo were subjected to statistical analysis. Values were represented as their mean \pm SE of three independent experiments and to compare the mean difference, one-way analysis of variance (ANOVA) with Tukey's post hoc test was carried out using SPSS statistical analysis software (Version 20.0, IBM SPSS)

\section{Abbreviations}

SCNA: Starch Casein Nitrate Agar; ISP: International Streptomyces Project; TLC: Thin Layer Chromatography; PDA: Potato Dextrose Agar; DAP: Diaminopimelic Acid; MTCC; Microbial Type Culture Collection; IAA: Indole Acetic Acid

\section{Declarations}

\section{Ethics approval and consent to participate}

Not applicable

\section{Consent for publication}

Not applicable

\section{Availability of data and material}

All data generated or analysed during this study are included in this article

\section{Competing interest}

The authors declare that they have no competing interest.

\section{Funding details}


This work was financially supported by DST-Promotion of University Research and Scientific Excellence scheme.

\section{Author contribution}

$\mathrm{RM}$ as research supervisor of SD and MS was involved in the planning of research work; investigation and interpretation of data; drafting and critical editing of the manuscript in terms of intellectual content. MS conducted and interpreted the data related to isolation of the strain and SD was involved in the planning and accomplishment of the research work; analysis and interpretation of data; manuscript writing following the suggestions of the research supervisor. All of the authors agreed to be responsible for all aspects of the writing, including ensuring that any concerns about the work's quality or credibility are thoroughly investigated and resolved. The manuscript has been read and accepted by all contributors.

\section{Acknowledgements}

We duly acknowledge Department of science \& technology for the financial support to accomplish this research work. One of the authors, Sapna Devi acknowledges the grant of fellowship under University with potential for Excellence scheme of DST- Promotion of University Research and Scientific.

\section{References}

1. Niu K, Guo H, Kakizaki M, Cui Y, Ohmori-Matsuda K, Guan L, Furukawa K. A tomato-rich diet is related to depressive symptoms among an elderly population aged 70 years and over: a population-based, cross-sectional analysis. J Affect Disord. 2013; doi: 10.1016/j.jad.2012.04.040.

2. Rais M, Sheoran. A Scope of supply chain managementin fruits and vegetables in India. J. Food Process.Technol. 2015; doi: 10.4172/2157-7110.1000427

3. FAO. World tomato production. Food and Agriculture Organization of the United Nations, Rome, Italy, 2018.

4. Shanmugasundaram S. The Hindu survey of Indian Agriculture. 2004; 127.

5. Ellis MB, Gibson IAS (1975) Alternaria solani no. 45 set 48. Commonwealth Mycological Institute, Kew, Surrey, UK.

6. Peralta IE, Knapp S, Spooner DM. New species of wild tomatoes (Solanum section Lycopersicon: Solanaceae) from northern Peru. Syst Bot. 30: 424-434.

7. Adulrahman Omer (2018) Diagnosis And In Vitro Control of Tomato Leaf Spot Caused by Alternaria alternata In Sulaimani Governorate. J ZankoySulaimani-For Pure and App Science 20: 637-650. https://doi.org /10.17656/jzs.10710

8. Rabiey M, Hailey L E, Roy S R, Grenz K, Al-Zadjali M A, Barrett G A, Jackson R W (2019). Endophytes vs tree pathogens and pests: can they be used as biological control agents to improve tree health. Eur. J. Plant Pathol 1-19. https://doi.org/10.1007/s10658-019-01814-y 
9. Kaur T, Rani R, Manhas R K (2019). Biocontrol and plant growth promoting potential of phylogenetically new Streptomyces sp. MR14 of rhizospheric origin. AMB Express 9: 125. https://doi.org/10.1186/s13568-019-0849-7

10. Li Y, Guo Q, He F, Li Y, Xue Q, Lai H (2019) Biocontrol of Root Diseases and Growth Promotion of the Tuberous Plant Aconitum carmichaelii Induced by Actinomycetes Are Related to Shifts in the Rhizosphere Microbiota. Micrb. Ecol 1-14. https://doi.org/ 10.1007/s00248-019-01388-6

11. Cuppels D A, Higham, J, Traquair J A (2013) Efficacy of selected streptomycetes and a streptomycete + pseudomonad combination in the management of selected bacterial and fungal diseases of field tomatoes. Biol control 67: 361-372. https://doi.org/10.1016/j.biocontrol.2013.09.005

12. Heydaria A, Pessarakli M (2010) A review on biological control of fungal plant pathogens using microbial antagonists. J Biol Sci 10: 273-290. https://doi.org/10.3923/jbs.2010.273.290

13. Goudjal Y, Zamoum M, Sabaou N, Mathieu F, Zitouni A. Potential of endophytic Streptomyces spp. For biocontrol of Fusarium root rot disease and growth promotion of tomato seedlings. Biocontrol sci techn. 2006; doi: 10.1080/09583157.2016.1234584.

14. Kanini G S, Katsifas E A, Savvides A L, Karagouni A D. Streptomyces rochei ACTA1551, an indigenous Greek isolate studied as a potential biocontrol agent against Fusarium oxysporum f. Sp. Lycopersici. Biomed Res Int. 2013; doi: 10.1155/2013/387230.

15. Karnwal A. Production of indole acetic acid by fluorescent Pseudomonas in the presence of Ltryptophan and rice root exudates. J Plant Pathol. 2009; doi: 10.4454/jpp.v91i1.624.

16. Goudjal X, Toumatia O, Sabaou N, Barakate M, Mathieu F, Zitouni A. Endophytic actinomycetes from spontaneous plants of Algerian Sahara: indole-3-acetic acid production and tomato plants growth promoting activity. World J. Microbiol. Biotechnol. 2013; doi: 10.1007/s11274-013-1344-y.

17. Lin L, Xu X (2013) Indole-3-acetic acid production by endophytic Streptomyces sp. En-1 isolated from medicinal plants. Curr Microbiol. 2013; doi:10.1007/s00284-013-0348-z.

18. Myo E M, Ge B, Ma J, Cui H, Liu B, Shi L, Zhang K (2019) Indole-3-acetic acid production by Streptomyces fradiae NKZ-259 and its formulation to enhance plant growth. BMC microbiol. 2019; doi:10.1186/s12866-019-1528-1.

19. Suarez Moreno, Z R, Vinchira-Villarraga D M, Vergara-Morales D I, Castellanos L, Ramos F A, Guarnaccia C, Moreno-Sarmiento N. Plant-growth promotion and biocontrol properties of three Streptomyces spp. Isolates to control bacterial rice pathogens. Front microbiol. 2019;doi: 10.3389/fmicb.2019.00290.

20. Cuppels D A, Higham, J, Traquair J A. Efficacy of selected streptomycetes and a streptomycete + pseudomonad combination in the management of selected bacterial and fungal diseases of field tomatoes. Biol control. 2013; doi:10.1016/j.biocontrol.2013.09.005.

21. Cao L, Qiu Z, Dai X, Tan H, Lin Y, Zhou S. Isolation of endophytic actinomycetes from roots and leaves of banana (Musa acuminata) plants and their activities against Fusarium oxysporumf. Sp. Cubense. World J MicrobBiot. 2004; doi:10.1023/B:WIBI.0000040406.30495.48. 
22. Bauer AW, Kirby WMM, Sherris JC, Turck M. Antibiotics susceptibility testingby a standardized single disc method. Am J Clin Patho. 1966; 45: 493.

23. Shirling EB, Gotllieb D. Methods for characterization of streptomycetes sp. Int J Syst Bacteriol. 1966; doi:10.1099/00207713-16-3-313.

24. Cowan ST, Steel KJ (1965) Manual for the Identification of Medical Bacteria. London: Cambridge University Press.

25. Lechevalier MPA, Lechevalier HA (1980). The chemotaxonomy of actinomycetes. In: Dietz, A. and Thayer, D.W. (eds.), Actinomycete taxonomy. pp. 22-291. Society for Industrial Microbiology.

26. Marmur J. A procedure for the isolation of deoxyribonucleic acid from microorganisms. J Mol Biol. 1961;doi:10.1016/S0022-2836(61)80047-8.

27. Chun J, Lee JH, Jung Y, Kim M, Kim S, Kim BK, Lim YW. EzTaxon: a webbased tool for the identifcation of prokaryotes based on 16S ribosomalRNA gene sequences. Int J Syst Evol. 2007; doi:10.1099/ijs.0.64915-0.

28. Saitou N, Nei M. The neighbor-joining method: a new method for reconstructing phylogenetic trees. Mol bio evol. 1987; doi:10.1093/oxfordjournals.molbev.a040454.

29. Tamura K, Stecher G, Peterson D, Filipski A, Kumar S. MEGA6: molecular evolutionary genetics analysis version 6.0. Mol Biol Evol. 2013;doi:10.1093/molbev/mst197.

30. Hassaan M A, El Nemr A. Pesticides pollution: Classifications, human health impact, extraction and treatment techniques. Egypt. J. Aquat. Res. 2020; org:10.1016/j.ejar.2020.08.007.

31. Elahi E, Weijun C, Zhang H, Abid M. Use of artificial neural networks to rescue agrochemical-based health hazards: A resource optimisation method for cleaner crop production. J Cleanr Prod. 2019; doi:10.1016/j.jclepro.2019.117900.

32. Mishra J, Arora N K. Secondary metabolites of fluorescent pseudomonads in biocontrol of phytopathogens for sustainable agriculture. Appl Soil Ecol. 2018; doi:10.1016/j.apsoil.2017.12.004.

33. Awla H K, Kadir J, Othman R, Rashid T S, Hamid S, Wong M Y. Plant growth-promoting abilities and biocontrol efficacy of Streptomyces sp. UPMRS4 against Pyriculariaoryzae. Biol control. 2017; doi:10.1016/j.biocontrol.2017.05.011.

34. Chen YF, Zhou DB, Qi DF, Gao ZF, Xie JH, Luo YP (2017) Growth promotion and disease suppression ability of a Streptomyces sp. CB-75 from Banana Rhizosphere Soil. Front Microbiol. 2017; doi: 10.3389/fmicb.2017.02704.

35. Law JWF, Ser HL, Khan TM, Chuah LH, Pusparajah P, Chan KG, Goh BH, Lee LH. The potential of Streptomyces as biocontrol agents against the rice blast fungus, Magnaportheoryzae (Pyriculariaoryzae). Front Microbiol. 2017; doi: 10.3389/fmicb.2017.00003.

36. Jeon BJ, Kim JD, Han JW, Kim BS. Antifungal activity of rimocidin and a new rimocidin derivative BU16 produced by Streptomyces mauvecolor BU16 and their effects on pepper anthracnose. J Appl Microbiol. 2016; doi:10.1111/jam.13071. 
37. Vurukonda SSKP, Giovanardi D, Stefani E (2018). Plant growth promoting and biocontrol activity of Streptomyces spp. as endophytes. Int. J. Mol. Sci. 2018; doi:10.3390/ijms19040952.

38. Kim B S, Hwang B K. (2007) Microbial fungicides in the control of plant diseases. J Phytopathology. 2007; doi:10.1111/j.1439-0434.2007.01314.x.

39. Cao L, Qiu Z, Dai X, Tan H, Lin Y, Zhou S. Isolation of endophytic actinomycetes from roots and leaves of banana (Musa acuminata) plants and their activities against Fusarium oxysporumf. Sp. Cubense. World J MicrobBiot. 2004; doi: 10.1023/B:WIBI.0000040406.30495.48.

40. Taechowisan T, Peberdy J F, Lumyong S. Isolation of endophytic actinomycetes from selected plants and their antifungal activity. World J. Microbiol. 2003; doi:10.1023/A:1023901107182.

41. Verma VC, Gond SK, Kumar A, Mehra A, Kharwar RN, Gange AC. Endophytic actinomycetes from Azadirachta indica A. Juss.: Isolation, Diversity, and Anti-microbial Activity. Microb Ecol. 2009; doi:10.1007/s00248-008-9450-3.

42. Verma VC, Singh S K, Prakash S. Bio-control and plant growth promotion potential of siderophore producing endophytic Streptomyces from Azadirachta indica A. Juss. J. Basic Microbiol. 2011; doi:10.1002/jobm.201000155.

43. Ranjan R, Jadeja V. Isolation, characterization and chromatography based purification of antibacterial compound isolated from rare endophytic actinomycetes Micrococcus yunnanensis. J Pharm Anal. 2017; doi:10.1016/j.jpha.2017.05.001.

44. Wei W, Zhou Y, Chen F, Yan X, Lai Y, Wei C, Wang X. Isolation, diversity, and antimicrobial and immunomodulatory activities of endophytic Actinobacteria from tea cultivars Zijuan and Yunkang10 (Camellia sinensis var. assamica). Front Microbiol. 2018; doi:10.3389/fmicb.2018.01304.

45. Sahu AK, Quadri SR, Agasar D, Al Ruwaili J, Jun-Li W, Dastager SG. Allostreptomycesindica sp. Nov., isolated from India. J antibiot. 2017; doi:10.1038/ja.2017.82.

46. Chen X, Hu LF, Huang XS, Zhao LX, Miao CP, Chen YW, Li YQ. Isolation and Characterization of New Phenazine Metabolites with Antifungal Activity against Root-Rot Pathogens of Panax notoginseng from Streptomyces. J. Agric. Food Chem. 2019; doi:10.1021/acs.jafc.9b04191.

47. Lyu A, Liu H, Che H, Yang L, Zhang J, Wu M, Li G. Reveromycins A and B from Streptomyces sp. 310: antifungal activity against plant pathogenic fungi in vitro and in a strawberry food model system. Front. Microbiol. 2017; doi:10.3389/fmicb.2017.00550.

48. Zhang K, Gu L, Zhang Y, Liu Z, Li X. Dinactin from a new producer, Streptomyces badius gz-8, and its antifungal activity against the rubber anthracnose fungus Colletotrichum gloeosporioides. Microbiol Res. 2020; doi:10.1016/j.micres.2020.126548.

49. Sharma M, Manhas RK. Purification and characterization of salvianolic acid B from Streptomyces sp. M4 possessing antifungal activity against fungal phytopathogens. Microbiol Res. 2020; doi:10.1016/j.micres.2020.126478.

50. Dhanasekaran D, Sivamani P, Panneerselvam A, Thajuddin N, Rajakumar G, Selvamani S. Biological control of tomato seedling damping off with Streptomyces sp. Plant Pathol. 2005; doi:10.3923/ppj.2005.91.95. 
51. Liu W H, Chen F, Wang C E, Fu H H, Fang XQ, Ye JR, Shi JY. Indole-3-acetic acid in Burkholderia pyrrocinia JK-SH007: enzymatic identification of the indole-3-acetamide synthesis pathway. Front. Microbiol. 2019; doi:10.3389/fmicb.2019.02559.

52. Myo E M, Ge B, Ma J, Cui H, Liu B, Shi L, Zhang K. Indole-3-acetic acid production by Streptomyces fradiae NKZ-259 and its formulation to enhance plant growth. BMC microbiol. 2019; doi:10.1186/s12866-019-1528-1.

53. Sadeghi A, Karimi E, Dahaji P A, Javid M G, Dalvand Y, Askari H. Plant growth promoting activity of an auxin and siderophore producing isolate of Streptomyces under saline soil conditions. World J. Microbiol. Biotechnol. 2012; doi: 10.1007/s11274-011-0952-7.

54. Shrivastava P, Kumar R, Yandigeri MS. In vitro biocontrol activity of halotolerant Streptomyces aureofaciens K20: A potent antagonist against Macrophomina phaseolina (Tassi) Goid. Saudi J Biol Sci. 2017; doi:10.1016/j.sjbs.2015.12.004.

55. Tamreihao K, Ningthoujam DS, Nimaichand S, Singh ES, Reena P, Singh SH, Nongthomba U. Biocontrol and plant growth promoting activities of a Streptomyces corchorusii strain UCR3-16 and preparation of powder formulation for application as biofertilizer agents for rice plant. Microbiol. Res. 2016; doi:10.1016/j.micres.2016.08.005.

56. Lin L, Xu X. Indole-3-acetic acid production by endophytic Streptomyces sp. En-1 isolated from medicinal plants. Curr Microbiol. 2013; doi:10.1007/s00284-013-0348-z.

57. Vurukonda SSKP, Giovanardi D, Stefani E. Plant growth promoting and biocontrol activity of Streptomyces spp. as endophytes. Int. J. Mol. Sci. 2018; doi: 10.3390/ijms19040952.

58. Khamna, S, Yokota A, Peberdy J F, Lumyong S. Indole-3-acetic acid production by Streptomyces sp. isolated from some Thai medicinal plant rhizosphere soils. EurAsian J. Biosci. 2010; doi:10.5053/ejobios.2010.4.0.4.

59. Goudjal X, Toumatia O, Sabaou N, Barakate M, Mathieu F, Zitouni A. Endophytic actinomycetes from spontaneous plants of Algerian Sahara: indole-3-acetic acid production and tomato plants growth promoting activity. World J. Microbiol. 2013; doi:10.1007/s11274-013-1344-y.

60. Dimkpa CO, Zeng J, McLean JE, Britt DW, Zhan J, Anderson AJ. Production of indole-3-acetic acid via the indole-3-acetamide pathway in the plant-beneficial bacterium Pseudomonas chlororaphis 06 is inhibited by ZnO nanoparticles but enhanced by CuO nanoparticles. Appl. Environ. Microbiol. 2012; doi:10.1128/AEM.07424-11.

61. Manulis S, Shafrir H, Epstein E, Lichter A, Barash I. Biosynthesis of indole-3-acetic acid via the indole3-acetamide pathway in Streptomyces spp. Microbiology. 1994; doi:10.1099/13500872-140-5-1045.

62. Li Q, Jiang Y., Ning, P., Zheng, L., Huang, J., Li, G., Jiang, D. and Hsiang, T. Suppression of Magnaportheoryzaeby culture filtrates of StreptomycesglobisporusJK-1. Biol Cont. 2011; doi: 10.1016/j.biocontrol.2011.04.013.

63. Kaur T, Rani R, Manhas RK. Biocontrol and plant growth promoting potential of phylogenetically new Streptomyces sp. MR14 of rhizospheric origin. AMB Express. 2019; doi:10.1186/s13568-019-0849-7. 
64. Shakeel Q, Lyu A, Zhang J, Wu M, Li G, Hsiang T, Yang L. Biocontrol of Aspergillus flavus on peanut kernels using Streptomyces yanglinensis 3-10. Front. Microbiol. 2018; doi: 10.3389/fmicb.2018.01049.

65. Wei Y, Zhao Y, Zhou D, Qi D F, Li K, Tang W, Wang W. A Newly Isolated Streptomyces sp. YYS-7 with a Broad-spectrum Antifungal Activity Improves the Banana Plant Resistance to Fusarium Oxysporum $\mathrm{f}$. sp. Cubense Tropical Race 4. Front. Microbiol. 2020; doi:10.3389/fmicb.2020.01712.

66. Awan Z A, Shoaib. Combating early blight infection by employing Bacillus subtilis in combination with plant fertilizers. Curr. Microbiol. 2019; doi:10.1016/j.cpb.2019.100125.

67. Attia M S, El-Sayyad GS, Abd Elkodous M, El-Batal Al. The effective antagonistic potential of plant growth-promoting rhizobacteria against Alternaria solani-causing early blight disease in tomato plant. Scientia Horticulturae. 2020; doi:10.1016/j.scienta.2020.109289.

68. Cuppels DA, Higham, J, Traquair JA. Efficacy of selected streptomycetes and a streptomycete + pseudomonad combination in the management of selected bacterial and fungal diseases of field tomatoes. Biol control. 2013; doi:10.1016/j.biocontrol.2013.09.005.

69. Khan N, Mishra A, Nautiyal CS. Paenibacillus lentimorbus B-30488r controls early blight disease in tomato by inducing host resistance associated gene expression and inhibiting Alternaria solani. Biol control. 2012; doi:10.1016/j.biocontrol.2012.03.010.

70. Ambrosini A, Beneduzi A, Stefanski T, Pinheiro FG, Vargas LK, Passaglia LMP. Screening of plant growth promoting rhizobacteria isolated from sun-flower (Helianthus annuusL.). Plant Soil. 2012; doi:10.1007/s11104-011-1079-1.

71. Dias MP, Bastos MS, Xavier VB, Cassel E, Astarita LV, Santarém ER. (2017) Plant growth and resistance promoted by Streptomyces spp. in tomato. Plant Physiol. Biochem. 2017; doi:10.1016/j.plaphy.2017.07.017.

72. Gopalakrishnan S, Upadhyaya Hd, Vadlamudi S, Humayun P, Vidya MS, Alekhya G, Singh A, Vijayabharathi R, Bhimineni R K, Seema M, Rathore A, Rupela O. Plant growth-promoting traits of biocontrol potential bacteriaisolated from rice rhizosphere. Springer Plus. 2012; doi:10.1186/21931801-1-71.

\section{Figures}



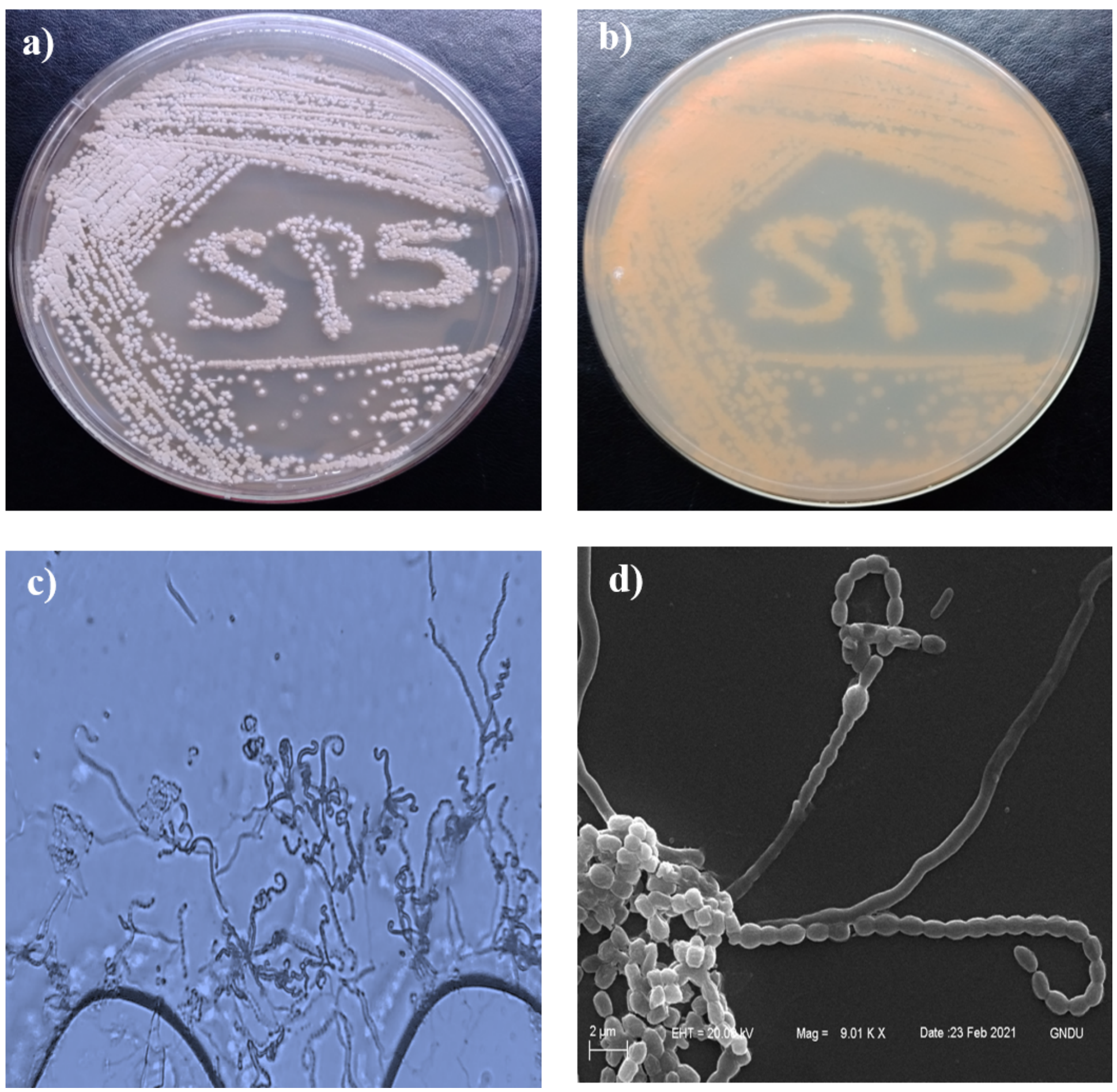

\section{Figure 1}

Streptomyces sp. SP5 morphological characteristics: a) Aerial mycelium, b) Substratum mycelium, c) Aerial hyphae spore chains having with open hook under Light Microscope (100X), d) Electron microscopic image of spores with smooth surface (Magnification $=9.01 \mathrm{KX}$ 


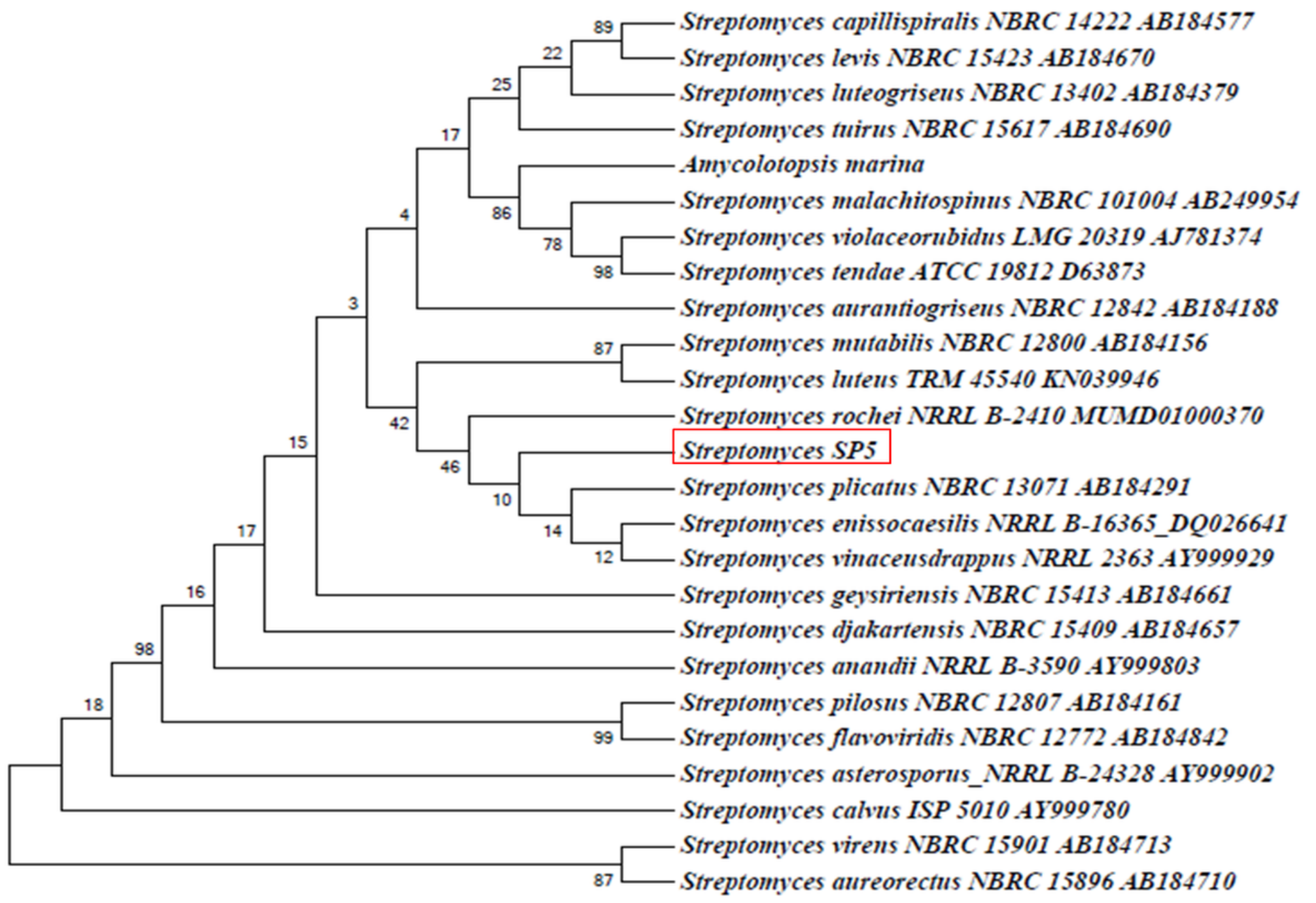

Figure 2

Maximum parsimony analysis of 16S rRNA gene sequences yielded a phylogenetic tree showing the relationship between SP5 and related Streptomyces species obtained from EzTaxon database. Bootstrap values are the numbers on branch nodes (expressed as percentage of 1,000 replications) 


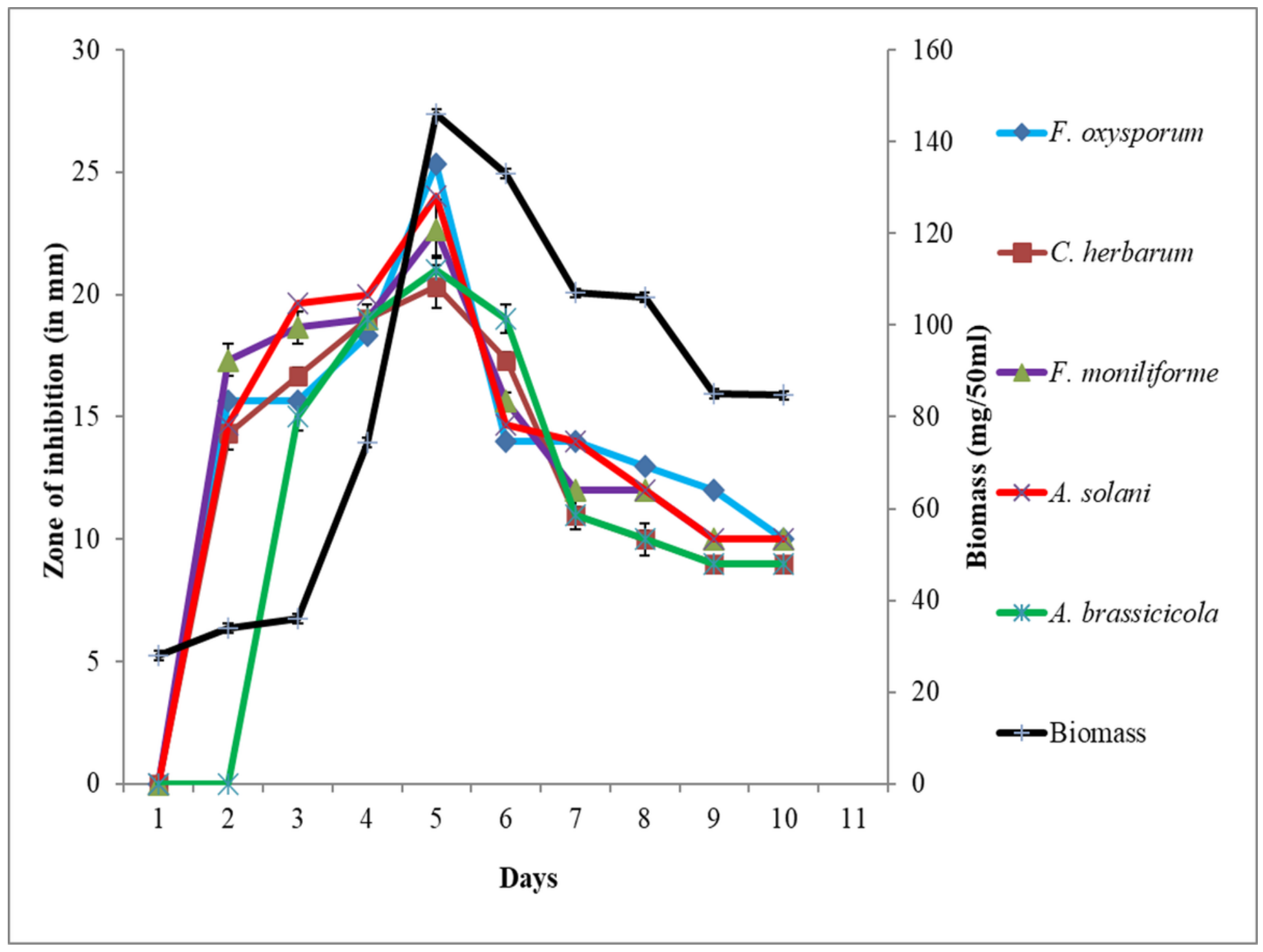

Figure 3

Growth and antifungal activity of Streptomyces sp. SP5 against test organisms viz. Fusarium oxysporum, Colletotrichum herbarum, Fusarium moniliforme, Alternaria solani and Alternaria brassicicola. 

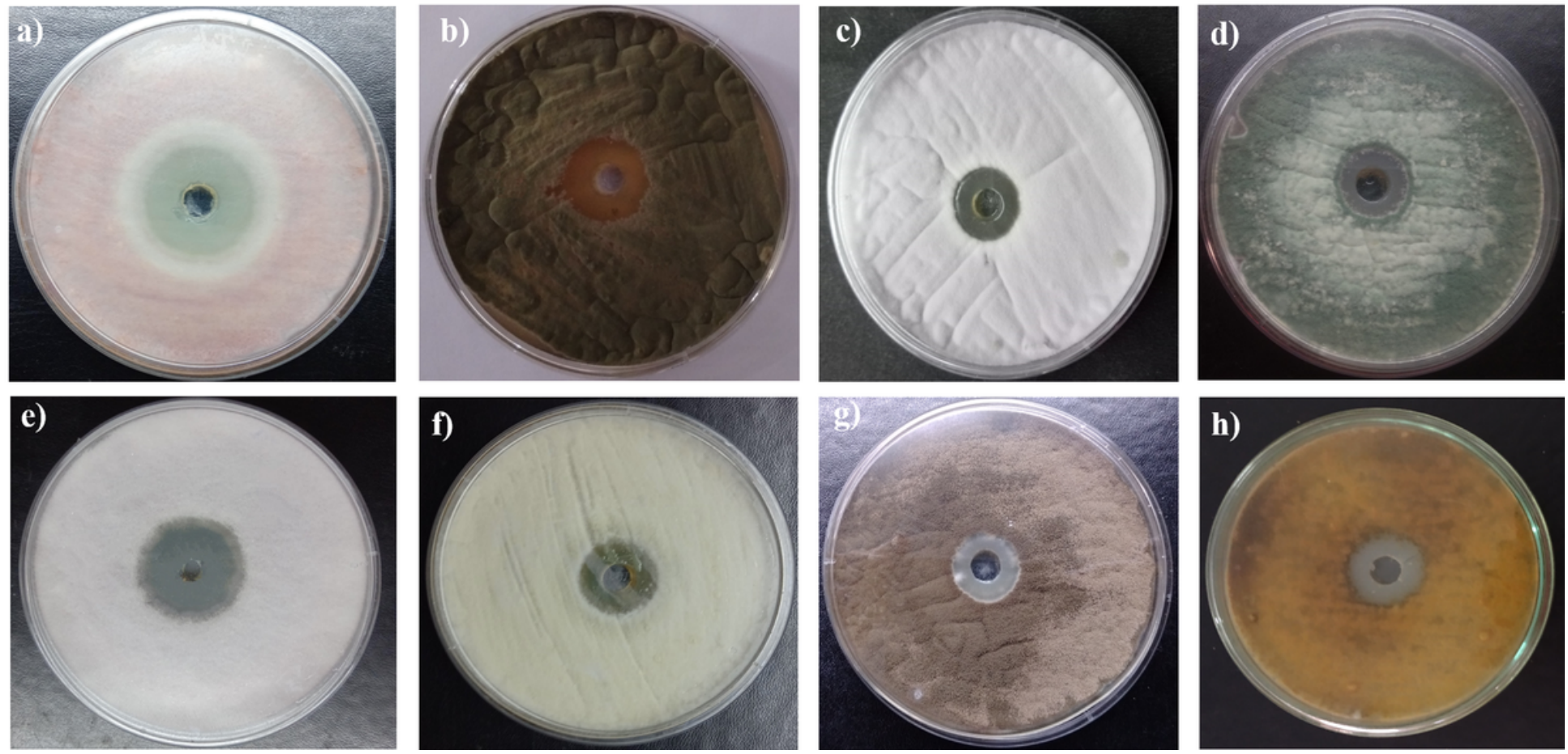

Figure 4

Antifungal activity of Streptomyces sp. SP5 by well diffusion method against fungal phytopathogens a) Fusarium moniliforme b) Cladosporium herbarum c) Colletotrichum acutatum d) Alternaria brassicicola e) Fusarium oxysporum f) Fusarium solani g) Alternaria solani h) Alternaria alternata. 

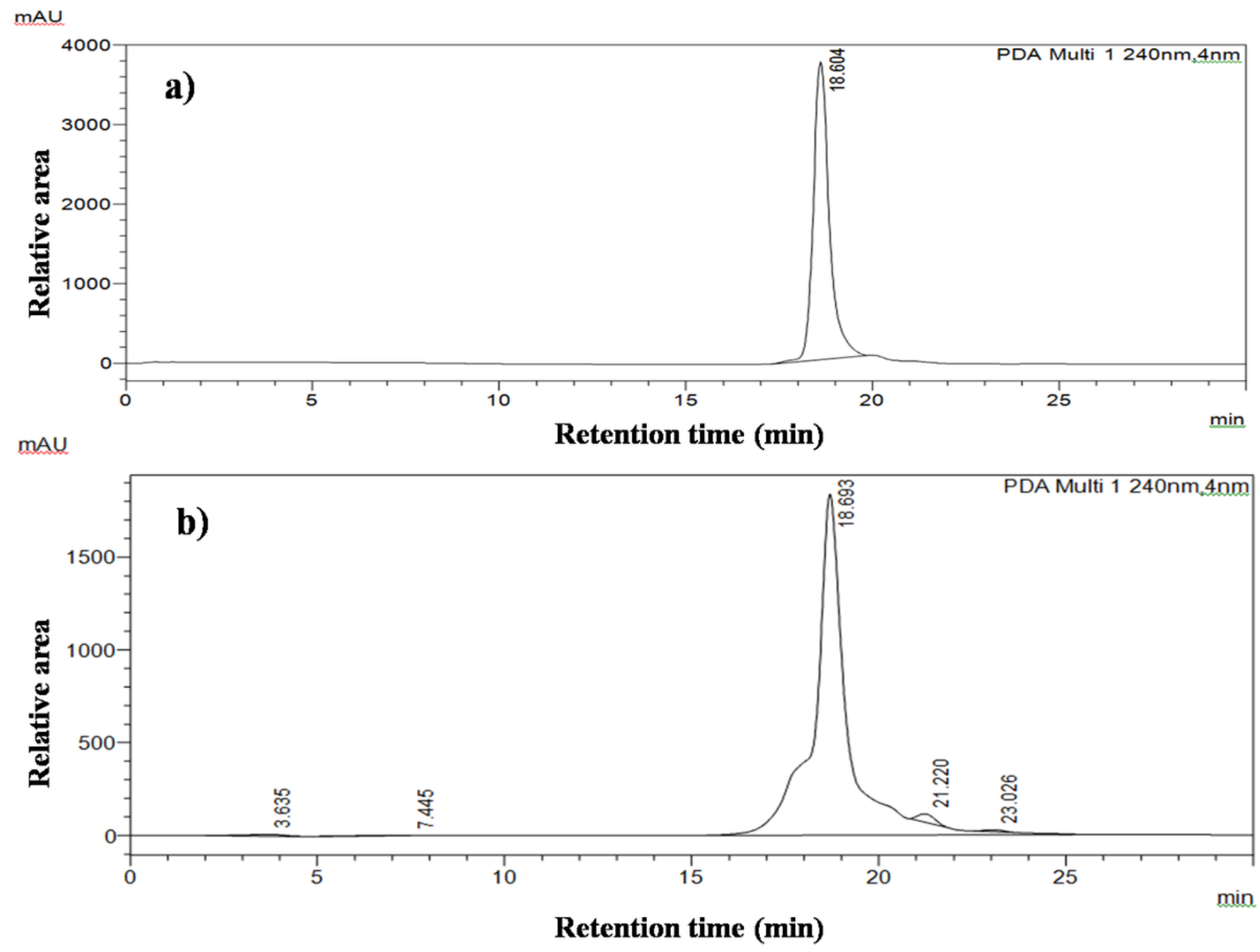

Figure 5

Semi preparative HPLC chromatogram of a) IAA standard and b) partial purified extract of culture filtrate of Streptomyces sp. SP5 

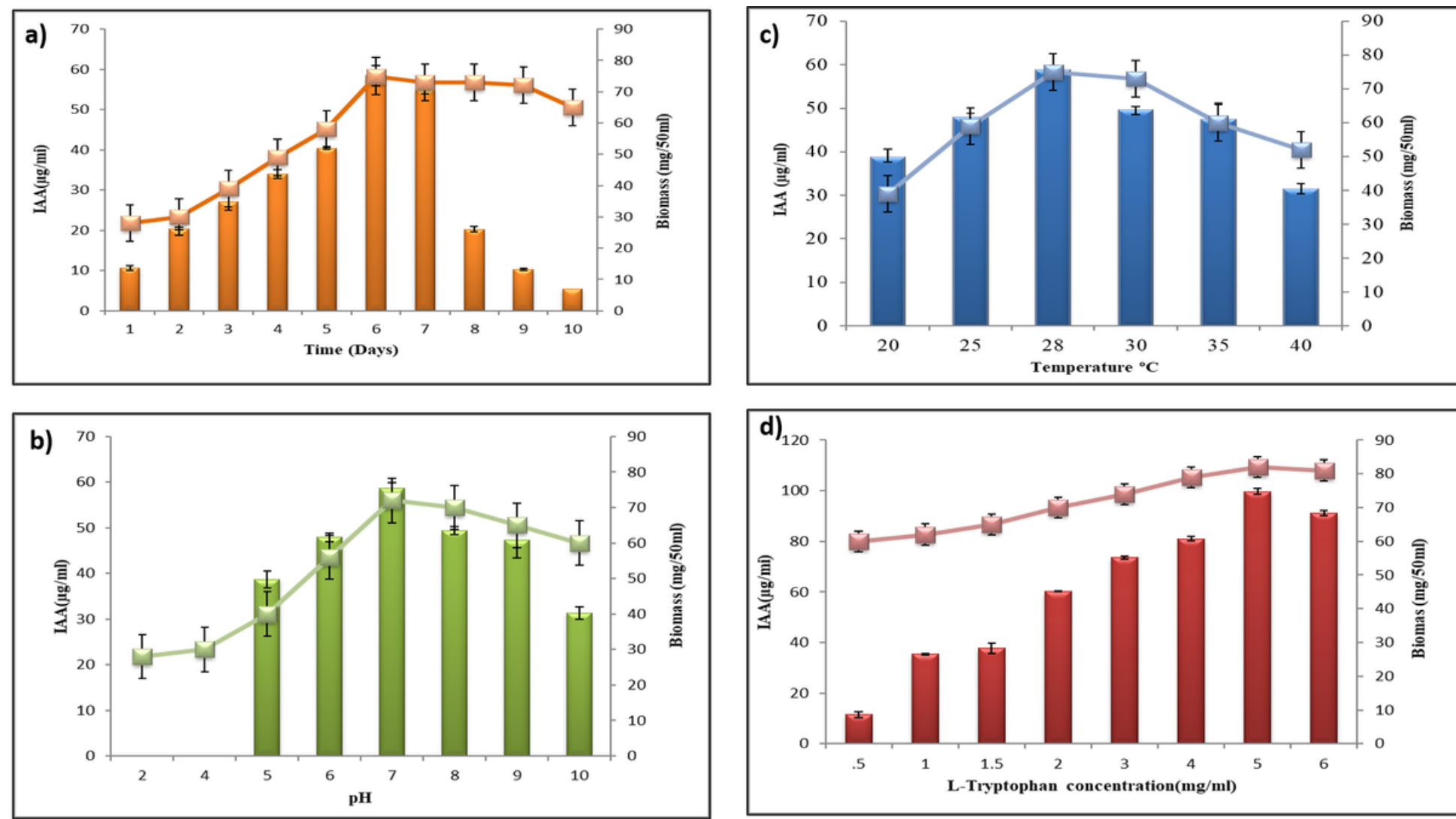

Figure 6

Streptomyces sp. SP5 produces IAA in response to (a): incubation period, (b): $\mathrm{pH}$, (c): temperature, and (d): tryptophan concentration. Columns and bars represent the mean $\pm \mathrm{SE}$ 

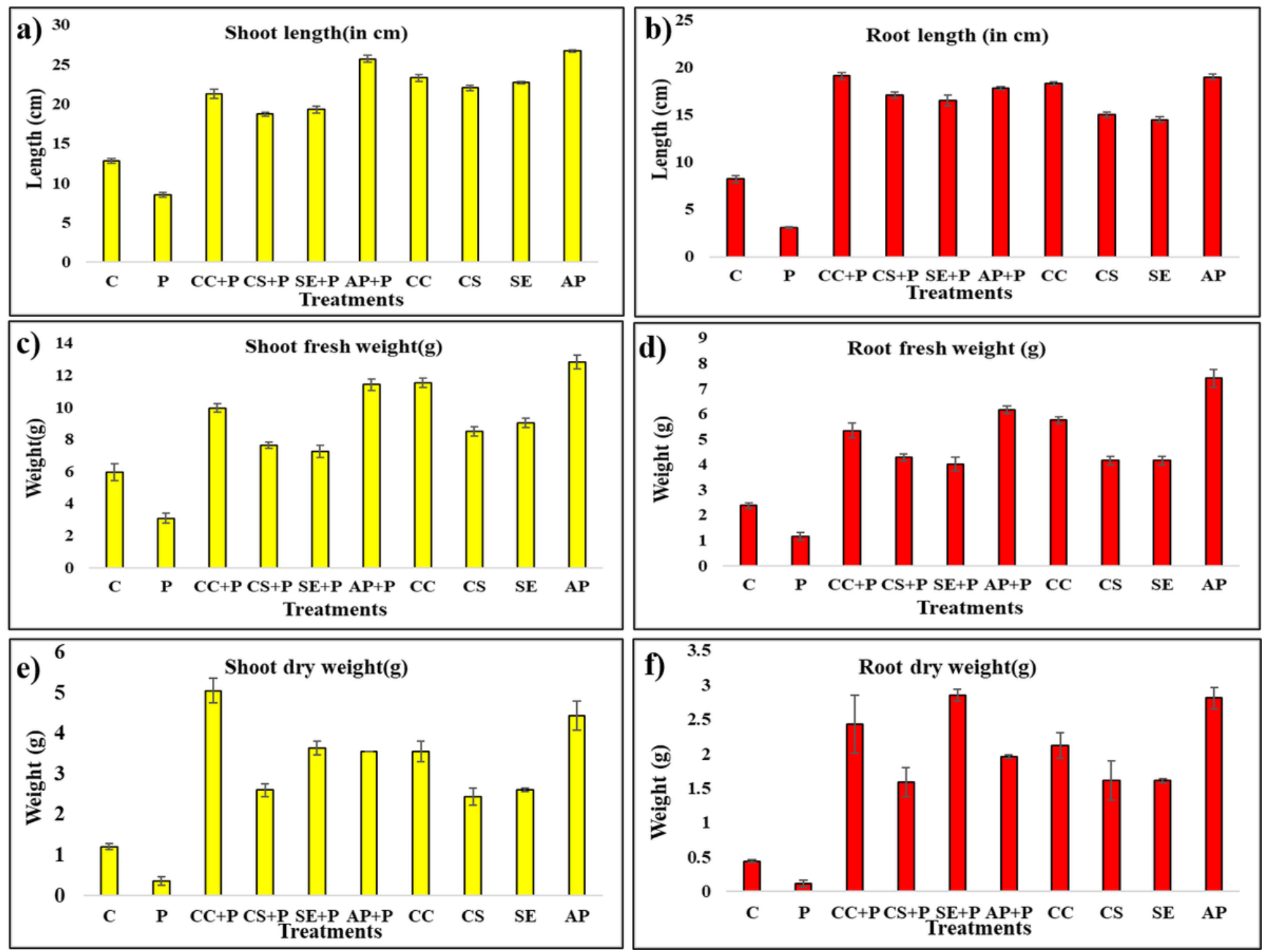

Figure 7

Effect of Streptomyces sp. SP5 and its metabolites as root treatments on S. lycopersicum (tomato) plants to control Alternaria solani causing Early blight disease a) shoot length, b) root length, c) shoot fresh weights, d) root fresh weights, e) shoot dry weight, f) root dry weight. Values were expressed in mean \pm standard error; $\mathrm{C}$, control (Water only). 


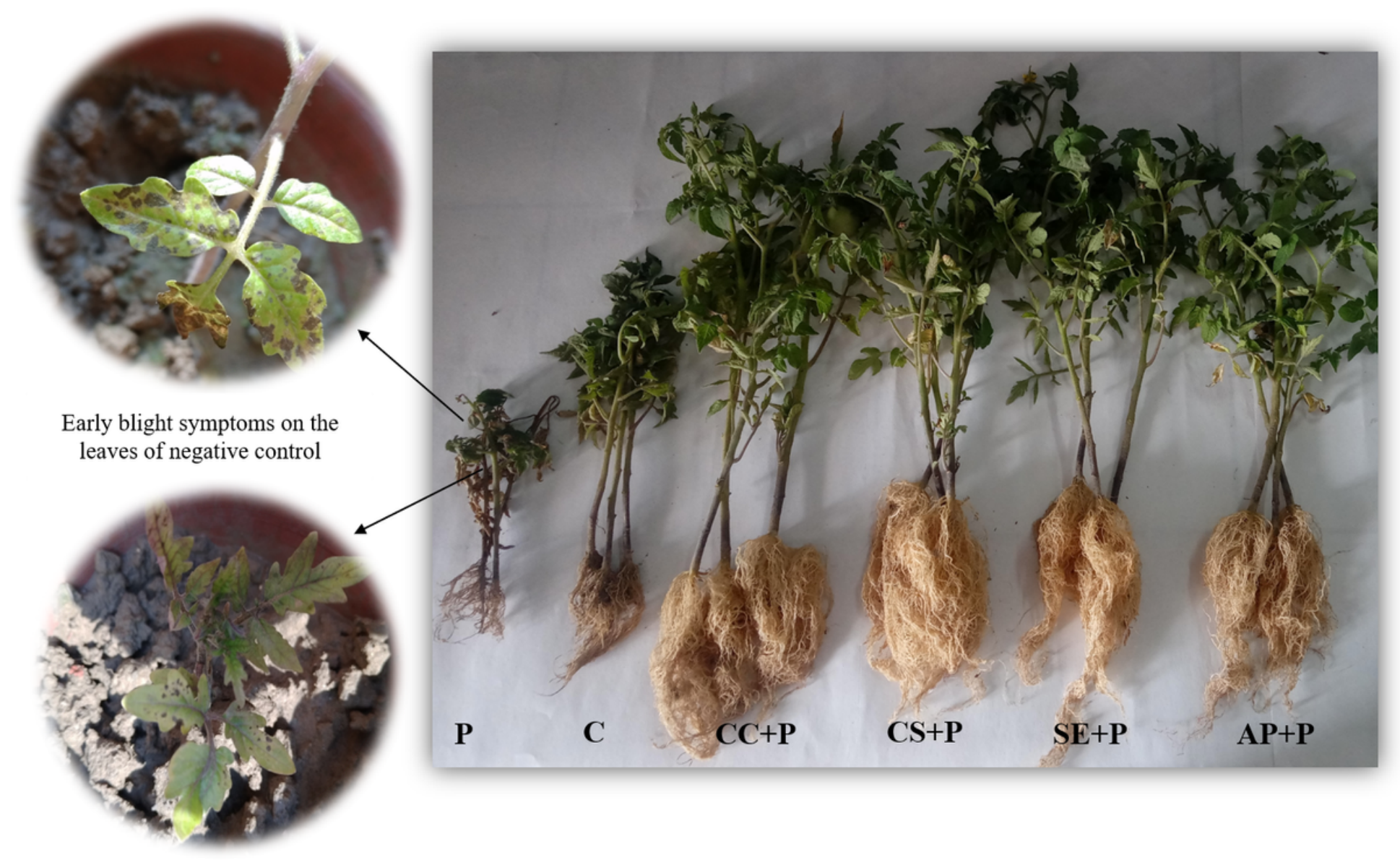

Figure 8

Effect of Streptomyces sp. SP5 and its metabolites on growth of S. lycopersicum (tomato) plants infested with Alternaria solani 


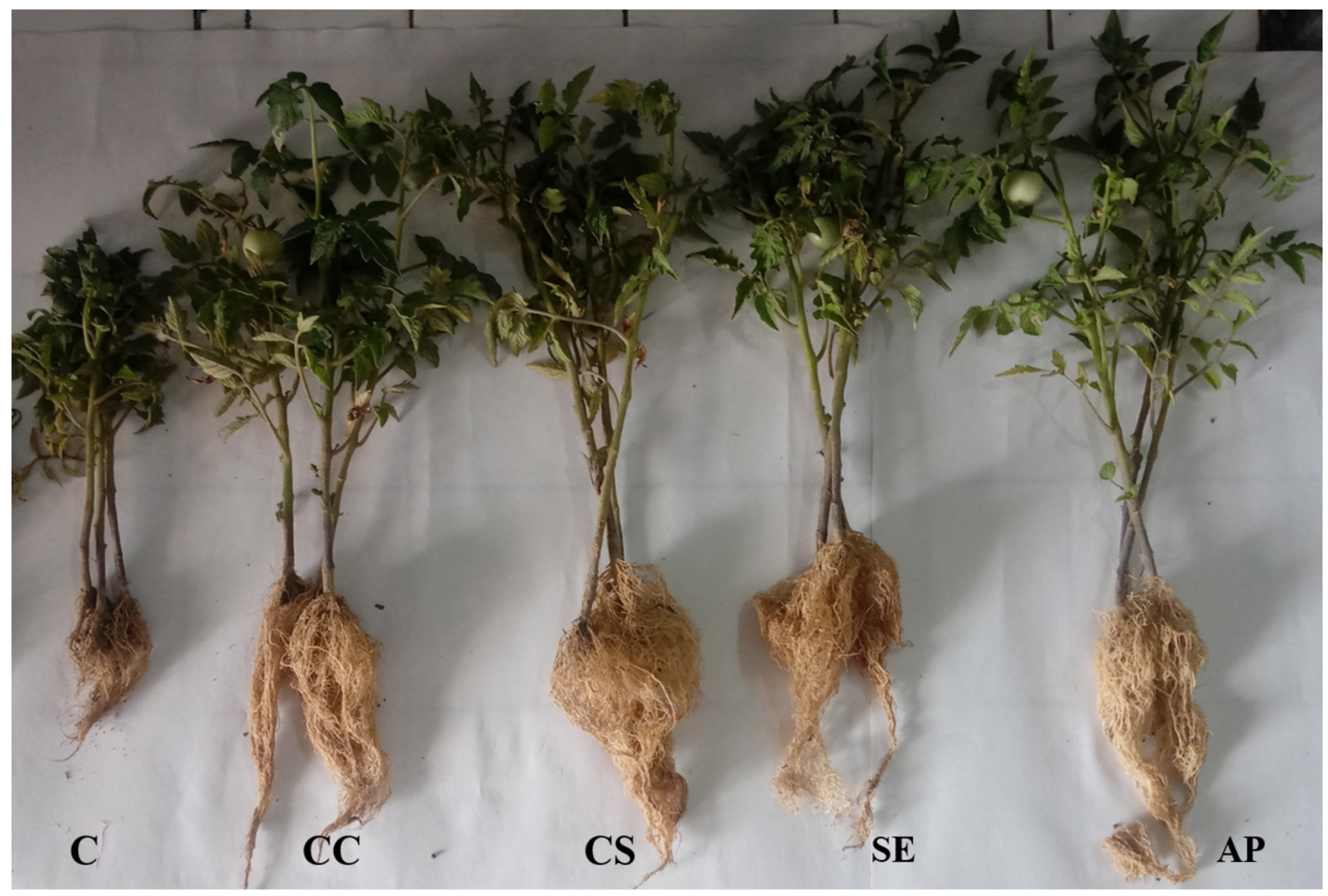

\section{Figure 9}

Plant growth promoting potential of Streptomyces sp. SP5 and its metabolites on growth of S. lycopersicum (tomato) plant

\section{Supplementary Files}

This is a list of supplementary files associated with this preprint. Click to download.

- supportivedata.docx 